\title{
Rotational spectroscopy of 2H,3H-perfluoropentane
}

\author{
Chinh H. Duong, ${ }^{1,2}$ Daniel A. Obenchain, ${ }^{1}$ S. A. Cooke,${ }^{3}$ Stewart E. Novick ${ }^{1, a}$
}

1. Department of Chemistry, Wesleyan University, Middletown, CT 06459

2. Present address, Department of Chemistry, Yale University, New Haven, CT 06520

3. School of Natural and Social Science, Purchase College SUNY, Purchase, NY 10577

a. corresponding author, snovick@wesleyan.edu

\section{Abstract}

The structure of $2 \mathrm{H}, 3 \mathrm{H}$-perfluoropentane, $\mathrm{CF}_{3} \mathrm{CHFCHFCF}_{2} \mathrm{CF}_{3}$, has been determine by a combination of Chirp-pulsed Fourier transform microwave (CP-FTMW) spectroscopy and cavity FTMW spectroscopy. Of the four possible stereoisomers, only the enantiomeric pair (R,R)/(S,S) were observed experimentally; there was no spectroscopic evidence for the enantiomeric pair $(\mathrm{R}, \mathrm{S}) /(\mathrm{S}, \mathrm{R})$. The conformeric structure of the $(\mathrm{R}, \mathrm{R}) /(\mathrm{S}, \mathrm{S})$ stereoisomer(s) was that of partial helices with $\mathrm{C}-\mathrm{C}-\mathrm{C}-\mathrm{C}$ dihedral angles of $12^{\circ}$ (helical) and $1^{\circ}$ (staggered). 


\section{$\underline{\text { Introduction }}$}

Previous structural studies of alkanes and perfluoroalkanes have concluded that alkanes have staggered structures where the hydrogen atoms along the chain have $\mathrm{C}-\mathrm{C}-\mathrm{C}-\mathrm{C}$ dihedral angles of $180^{\circ}$, while perfluoroalkanes with four or more carbons along the carbon chain display a helical $\mathrm{C}_{2}$ geometry with the $\mathrm{C}-\mathrm{C}-\mathrm{C}-\mathrm{C}$ dihedral angles of approximately $15-17$. $^{1}$ The staggered structure of $\mathrm{C}_{5} \mathrm{H}_{12}$ and the helical structure of $\mathrm{C}_{5} \mathrm{~F}_{12}$ are shown in Figure 1. These results have led to an interest in identifying the structure of fluorinated alkane chains with various substituents. In this study, the rotational spectrum of all carbon-12 $2 \mathrm{H}, 3 \mathrm{H}$-perfluoropentane $\left(\mathrm{H}_{2} \mathrm{PFP}\right)$, and all five singly-substituted ${ }^{13} \mathrm{C}$ isotopologues were observed and assigned.

A racemic sample of $2 \mathrm{H}, 3 \mathrm{H}$-perfluoropentane contains a mixture of four stereoisomers labeled as either "R" or "S" about each of the chiral centers, carbons " 2 " and "3". 2 Since both carbon-2 and carbon-3 are chiral centers in $\mathrm{H}_{2} \mathrm{PFP}$, there are four possible stereoisomers, $(\mathrm{S}, \mathrm{S}),(\mathrm{R}, \mathrm{R})$, $(\mathrm{R}, \mathrm{S})$, and $(\mathrm{S}, \mathrm{R})$. The $(\mathrm{S}, \mathrm{S})$ and $(\mathrm{R}, \mathrm{R})$ structures are enantiomers of each other, as are the $(\mathrm{R}, \mathrm{S})$ and $(\mathrm{S}, \mathrm{R})$ isomers. This means that they have the same conformeric form and energies, but are mirror images of each other. Since $(S, S)$ and $(R, R)$ are mirror images, they will have identical moments of inertia tensors and thus identical microwave spectra. The same holds true for the $(\mathrm{R}, \mathrm{S}) /(\mathrm{S}, \mathrm{R})$ pair. Only in an achiral environment will enantiomers be distinguishable. Recently, it has been shown that this can be achieved by microwave spectroscopy, ${ }^{3,4}$ but not in the current experiments.

\section{$\underline{\text { Experimental }}$}

A racemic mixture of $2 \mathrm{H}, 3 \mathrm{H}$-perfluoropentane $\left(\mathrm{H}_{2} \mathrm{PFP}\right)$ was purchased from SynQuest Laboratories. Approximately $2 \mathrm{ml}$ of the racemic mixture was injected into a polyethylene tube and isolated from air to prevent contamination of the spectra due to atmospheric gases. Argon carrier gas was then bubbled through the sample at a pressure of approximately 50 psi. In this study, the rotational spectrum of all carbon- $12 \mathrm{H}_{2} \mathrm{PFP}$, was observed and assigned using a chirped-pulse Fourier transform microwave (CP-FTMW) spectrometer. ${ }^{5}$ An average of 10,000 
gas pulses for every $2 \mathrm{GHz}$ section from 7-15 GHz was collected on the Chirp. All five ${ }^{13} \mathrm{C}$ isotopologues were observed and characterized on a Balle-Flygare type cavity spectrometer. ${ }^{6}$ Given a racemic sample of $2 \mathrm{H}, 3 \mathrm{H}$-perfluoropentane with four available structural isomers, only the $(\mathrm{S}, \mathrm{S}) /(\mathrm{R}, \mathrm{R})$ structure was observed in the broadband spectrum, and it is the ${ }^{13} \mathrm{C}$ isotopologues of these enantiomers that were observed in the cavity spectrometer.

\section{$\underline{\text { Calculations }}$}

An ab initio scan of the $\mathrm{C}_{1}-\mathrm{C}_{2}-\mathrm{C}_{3}-\mathrm{C}_{4}$ dihedral angle of $2 \mathrm{H}, 3 \mathrm{H}$-perfluoropentane was performed using a low-level MP2/3-21g method and basis set from Gaussian $09^{7}$ to identify potential minima as the starting point for full optimizations. Two minimum energy conformations were found in the scan for the $(\mathrm{R}, \mathrm{R}) /(\mathrm{S}, \mathrm{S})$ enantiomers but only one minimum energy conformation was found in the scan for the $(\mathrm{R}, \mathrm{S}) /(\mathrm{S}, \mathrm{R})$ enantiomers. These structures from the low-level calculations were then fully optimized using an MP2/6-311++g $(2 \mathrm{~d}, 2 \mathrm{p})$ method and basis. These structures are shown in Figure 2 and the relative energies, rotational constants, and dipole moments from the calculation are given in Table 1.

\section{$\underline{\text { Results and Discussion }}$}

The observed transitions and their assignments for the six isotopologues are given in Supplementary Tables S1 - S6. Only $c$-type transitions were observed and assigned. Some very weak unassigned transitions are perhaps $b$-type transitions. Table 2 gives the spectroscopic constants of the normal isotopologue of $2 \mathrm{H}, 3 \mathrm{H}$-perfluoropentane and of its five singlysubstituted ${ }^{13} \mathrm{C}$ isotopologues. From comparisons of the predicted and observed rotational constants, it is clear that we are only observing the lowest energy trans conformation of the $(\mathrm{R}, \mathrm{R}) /(\mathrm{S}, \mathrm{S})$ enantiomer. The cis conformer was not observed on the CP-FTMW spectrometer, probably because its energy is $\sim 160 \mathrm{~cm}^{-1}$ above that of the trans conformer (see Table 1). Without a high energy barrier between the two conformers, the supersonic expansion cools the molecules only into the low energy conformation. The fact that we only observe strong $c$-type spectra is consistent with our assignment of the observed conformer to the trans $(\mathrm{R}, \mathrm{R}) /(\mathrm{S}, \mathrm{S})$ 
structure, but is not definitive. Since our chemical sample of $\mathrm{H}_{2} \mathrm{PFP}$ is purported to be a racemic mixture, we should also have observed the lowest energy conformation of the $(R, S) /(S, R)$ enantiomeric pair, but we did not. We can conclude that the $(\mathrm{R}, \mathrm{S}) /(\mathrm{S}, \mathrm{R})$ isomers, given the small values of the dipole moments for the low energy trans conformation, as given in Table 1, were not present in sufficient quantity in our sample for us to observe in the Chirp experiment. While the higher energy cis conformation of the $(\mathrm{R}, \mathrm{S}) /(\mathrm{S}, \mathrm{R})$ enantiomers, at $794 \mathrm{~cm}^{-1}$ relative to 180 $\mathrm{cm}^{-1}$, has a large $c$ dipole, it is not populated in our jet.

From the rotational constants from the six isotopologues of $\mathrm{H}_{2} \mathrm{PFP}$ as given in Table 2, we are able to calculate the $r_{\mathrm{s}}$, or Kraitchman coordinates of the five carbon atoms in the chain. Since the Kraitchman calculation only yields the absolute value of the coordinates, we give the signs of the coordinates from the MP2/6-311++g(2d,2p) calculation. In those two cases where the coordinates are so close to a principal axis that the Kraitchman calculation gives an imaginary value, the coordinate from the $a b$ initio calculation is given. These $r_{\mathrm{s}}$ and $a b$ initio coordinates of $\mathrm{H}_{2} \mathrm{PFP}$, in the principal axis system of the all carbon-12 isotopologue, are given in Table 3 . The structure of the all-trans $(\mathrm{R}, \mathrm{R})$ enantiomer, found in the experiment, is presented in Figure 2. Since we have not measured the fluorine or the hydrogen positions, the structure presented in Figure 2 is the $a b$ initio calculated structure, adjusted to the experimentally measured $\mathrm{C}-\mathrm{C}-\mathrm{C}-\mathrm{C}$ dihedral angles of $11.74^{\circ}$ and $1.04^{\circ}$ from $180^{\circ}$ for dihedral angles $\mathrm{C}_{1}-\mathrm{C}_{2}-\mathrm{C}_{3}-\mathrm{C}_{4}$ and $\mathrm{C}_{2}-\mathrm{C}_{3}-\mathrm{C}_{4}-\mathrm{C}_{5}$, respectively. The first of these angles is consistent with a helical geometry and the second angle is consistent with a staggered structure.

So, this answers the question we set out to ask: is the structure of $2 \mathrm{H}, 3 \mathrm{H}$-perfluoropentane helical like that of a fluorocarbon, or staggered like that of a hydrocarbon. Answer: both.

\section{$\underline{\text { Acknowledgements }}$}

We acknowledge the support of the National Science Foundation (NSF) grant CHE-1011214. We thank Wesleyan University for computer time supported by the NSF under Grant No. CNS0619508. 
Table 1. 2H,3H-perfluoropentane, ab initio ${ }^{\text {a }}$ relative energies, rotational constants, and dipole moments

$\begin{array}{llllllll}(\mathrm{R}, \mathrm{R}) /(\mathrm{S}, \mathrm{S}) & \text { Energy/ } \mathrm{cm}^{-1 \mathrm{~b}} & A / \mathrm{MHz} & B / \mathrm{MHz} & C / \mathrm{MHz} & \mu_{\mathrm{a}} / \mathrm{D} & \mu_{\mathrm{b}} / \mathrm{D} & \mu_{\mathrm{c}} / \mathrm{D} \\ \text { trans conformer } & 0 & 1204.73 & 339.94 & 332.81 & 0.10 & 0.56 & 1.84 \\ \text { cis conformer } & 163 & 1108.10 & 381.24 & 365.07 & 0.26 & 0.90 & 1.56 \\ \begin{array}{l}\mathrm{R}, \mathrm{S}) /(\mathrm{S}, \mathrm{R}) \\ \text { trans conformer }\end{array} & 180 & 1221.02 & 350.95 & 322.89 & 0.13 & 0.27 & 0.14 \\ \text { cis conformer } & 794 & 1140.22 & 396.41 & 369.87 & 0.64 & 0.27 & 2.19\end{array}$

a. At the MP2/6-311++g(2d,2p) level of theory and basis

b. Energy relative to the lowest energy conformation 
Table 2. Spectroscopic constants ${ }^{\text {a }}$ of $2 \mathrm{H}, 3 \mathrm{H}$-perfluoropentane and its isotopologues

\begin{tabular}{|c|c|c|c|c|c|c|}
\hline Parameter & Parent & ${ }^{13} \mathrm{C}(1)$ & ${ }^{13} \mathrm{C}(2)$ & ${ }^{13} \mathrm{C}(3)$ & ${ }^{13} \mathrm{C}(4)$ & ${ }^{13} \mathrm{C}(5)$ \\
\hline$A / \mathrm{MHz}$ & $1208.3387(2)$ & 1208.06482(4) & $1207.30327(6)$ & $1208.10028(8)$ & $1207.55696(7)$ & $1208.01824(6)$ \\
\hline$B / \mathrm{MHz}$ & $336.90086(5)$ & $335.35038(5)$ & $336.50271(8)$ & $336.91668(10)$ & $336.59260(7)$ & $335.54300(8)$ \\
\hline$C / \mathrm{MHz}$ & $329.24675(6)$ & $327.76299(6)$ & $328.80708(11)$ & $329.24601(10)$ & $328.91641(13)$ & $327.92397(10)$ \\
\hline$\Delta_{\mathrm{J}} / \mathrm{kHz}$ & $0.00550(6)$ & $0.0049(2)$ & $0.0052(3)$ & $0.0049(2)$ & $0.0048(4)$ & $0.0049(3)$ \\
\hline$\Delta_{\mathrm{K}} / \mathrm{kHz}$ & $0.063(4)$ & {$[0.063]$} & {$[0.063]$} & {$[0.063]$} & {$[0.063]$} & {$[0.063]$} \\
\hline$\Delta_{\mathrm{JK}} / \mathrm{kHz}$ & $0.0167(3)$ & {$[0.0167]$} & {$[0.0167]$} & {$[0.0167]$} & {$[0.0167]$} & {$[0.0167]$} \\
\hline$\delta_{\mathrm{J}} / \mathrm{kHz}$ & $-0.00011(2)$ & {$[-0.00011]$} & {$[-0.00011]$} & {$[-0.00011]$} & {$[-0.00011]$} & {$[-0.00011]$} \\
\hline$\delta_{\mathrm{K}} / \mathrm{kHz}$ & $0.148(7)$ & {$[0.148]$} & {$[0.148]$} & {$[0.148]$} & {$[0.148]$} & {$[0.148]$} \\
\hline $\mathrm{N}$ & 182 & 11 & 12 & 20 & 12 & 12 \\
\hline RMS / kHz & 6.0 & 0.3 & 0.6 & 1.0 & 0.6 & 0.6 \\
\hline
\end{tabular}

a. values in square brackets are not fitted, but are held fixed. This is the case for four of the five quartic centrifugal distortion constant for the C-13 isotopologues, whose values are held to those of the normal isotopologue. 
Table 3. Positions of the carbon backbone atoms from Kraitchman analysis ${ }^{\mathrm{a}}$ from ${ }^{13} \mathrm{C}$ substitution and $a b$ initio calculations ${ }^{\mathrm{b}}$, in $\AA$, in the principal axis system of the all- ${ }^{12} \mathrm{C}$ isotopologue.

\section{from Kraitchman}

Atom $a$

$\mathrm{C}_{1} \quad-2.6265(6) \quad-0.233(6)$

$\mathrm{C}_{2} \quad-1.317(1) \quad 0.564(3)$

$\mathrm{C}_{3} \quad[-0.113] \quad-0.280(5)$

$\mathrm{C}_{4} \quad 1.150(1)$

0.468(3)

$-0.342(4)$ $c$

$-0.203(7)$

$-0.202(7)$

$0.06(2)$

$-0.228(7)$

[-0.007]

\section{from ab initio}

a

$-2.630$

$-1.346$

$-0.113$

1.178

2.471 $b$

$-0.256$

0.566

$-0.289$

0.455

$-0.344$ c

$-0.202$

$-0.198$

0.070

$-0.265$

$-0.007$

a. The signs of the Kraitchman coordinates are those of the ab initio calculated values. In those cases where the Kraitchman coordinates are calculated to be imaginary, the values given in square brackets are from the ab initio calculation.

b. MP2/6-311++g(2d,2p) using Gaussian 09. 
Figure 1. The staggered structure of $\mathrm{C}_{5} \mathrm{H}_{12}$ and the helical structure of $\mathrm{C}_{5} \mathrm{~F}_{12}$ as given by a hf/6$311++\mathrm{g}(\mathrm{d}, \mathrm{p})$ and $\mathrm{b} 3 \mathrm{lyp} / 3-21 \mathrm{~g}$ ab initio calculations, respectively.
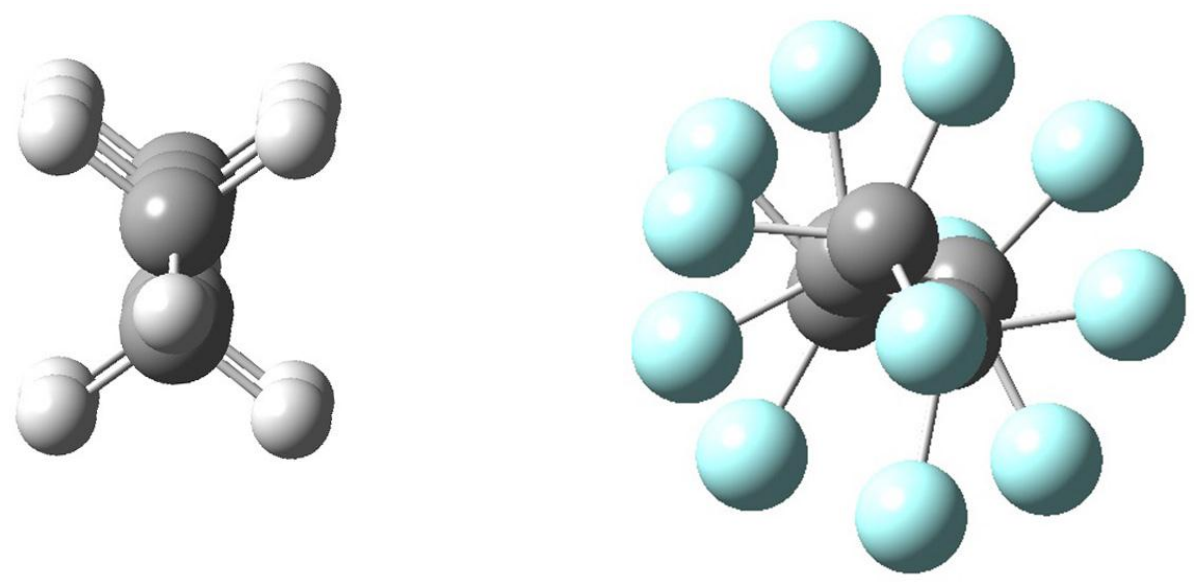
Figure 2. The structure of $2 \mathrm{H}, 3 \mathrm{H}-$ perfluoropentane.
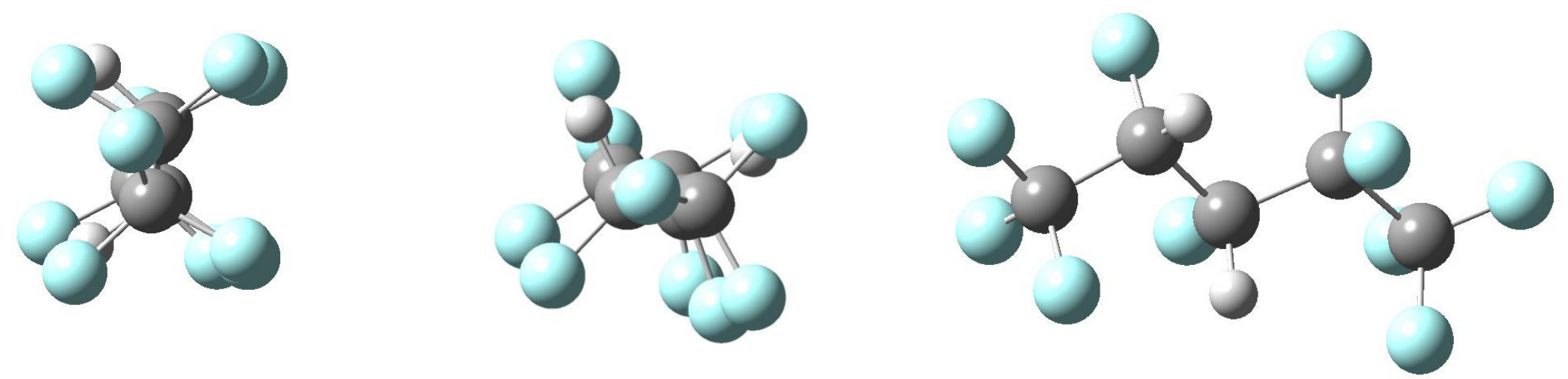

Figure caption. On the left is the view along the chain with $\mathrm{C}(5)$ in the foreground; in the middle is the view along the chain with $\mathrm{C}(1)$ in the foreground; on the right is the view displaying the chain of this trans-trans conformation of the (R,R) isomer. The structures presented are the $a b$ initio calculated structures, but with the $\mathrm{C}-\mathrm{C}-\mathrm{C}-\mathrm{C}$ dihedral angles adjusted to the experimentally determined values. 


\section{$\underline{\text { References }}$}

1. J. A. Fournier, R. K. Bohn, J. A. Montgomery, Jr., M. Onda, J. Phys. Chem. A 114, 1118-1122 (2010).

2. Any organic chemistry textbook will explain this R/S chiral center notation. Here is a nice example on the web: http://www.chem.sc.edu/faculty/shimizu/333/Chem_333/5a.vii.html

3. V. A. Shubert, D. Schmitz, C. Medcraft, A. Krin, D. Patterson, J. M. Doyle, M. Schnell, J. Chem. Phys. 142, 214201 (2015).

4. J.-U. Grabow, Ang. Chem. Int. Ed. 52, 11698-11700 (2013).

5. G. S. Grubbs II, C. T. Dewberry, K. C. Etchison, K. E. Kerr, S. A. Cooke, Rev. Scient. Instrum. 78, 096106 (2007).

6. A. R. Hight Walker, W. Chen, S. E. Novick, B. D. Bean, and M. D. Marshall, J. Chem. Phys. 102, 7298 (1995).

7. M. J. Frisch, et al, Gaussian 09, Gaussian Inc., Wallingford, CT (2009). 


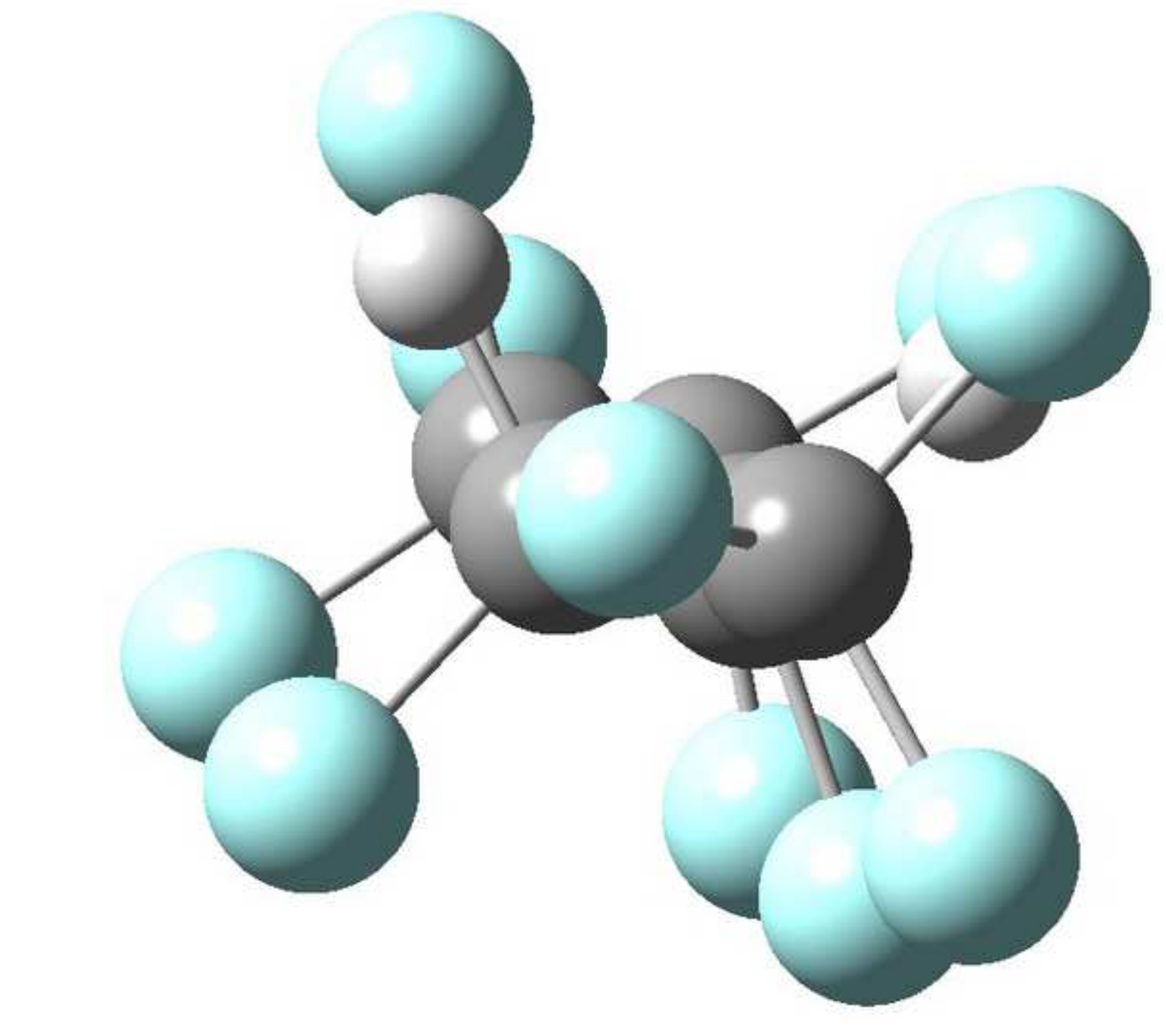

${ }^{*}$ Graphical Abstract

\author{
hical Abstract
}

